\title{
A INTERDISCIPLINARIDADE NOS ESTUDOS SOCIOJURÍDICOS: A EXPERIÊNCIA EDITORIAL DA REVISTA DROIT ET SOCIÉTÉ
}

\author{
THE INTERDISCIPLINARITY IN SOCIO-LEGAL STUDIES:
}

THE EDITORIAL EXPERIENCE OF THE JOURNAL DROIT ET SOCIÉTÉ

\section{Orlando Villas Bôas Filho*}

\begin{abstract}
Resumo:
Este artigo tem o intuito de analisar a questão da interdisciplinaridade nos estudos sociojurídicos a partir da expressiva experiência editorial da revista Droit et Société. Para tanto, em primeiro lugar, realiza uma concisa alusão à proposta de AndréJean Arnaud de desenvolvimento dos estudos sociojurídicos como um "campo de pesquisa interdisciplinar" e à "sociologia política do direito" de Jacques Commaille. Em seguida, com o propósito de explicitar uma das razões fundamentais da escolha dos trabalhos de Susan Silbey como objeto do dossiê do centésimo número da referida publicação, o artigo faz uma breve incursão pela obra da autora americana ressaltando, fundamentalmente, o seu contorno interdisciplinar. Por fim, o artigo consigna um sucinto exame da recepção dos Legal Consciousness Studies e, em particular, do pensamento de Susan Silbey, no âmbito dos estudos sociojurídicos na França, com especial ênfase nas afinidades existentes entre eles e a "sociologia política do direito" proposta por Jacques Commaille.

Palavras-chave: Estudos sociojurídicos. Interdisciplinaridade.Legal Consciousness Studies. Susan Silbey. Revue Droit et Société.
\end{abstract}

\begin{abstract}
:
This paper intends to analyze the issue of interdisciplinarity in socio-legal studies from the expressive editorial experience of the journal Droit et Société. To this end, it first concisely alludes to André-Jean Arnaud's proposal for the development of socio-legal studies as an "interdisciplinary field of research" and to Jacques Commaille's "political sociology of law". Then, with the purpose of explaining one of the fundamental reasons for choosing Susan Silbey's works as the subject of the hundredth issue of this Journal, the article makes a brief incursion into the work of Susan Silbey, emphasizing, fundamentally, its interdisciplinary outline. Finally, the article examines the reception of Legal Consciousness Studies and, in particular, Susan Silbey's thought in the context of socio-juridical studies in France, with special accent on the affinities between them and the "political sociology of law" proposed by Jacques Commaille.
\end{abstract}

Keywords: Socio-Legal Studies. Interdisciplinarity. Legal Consciousness Studies. Susan Silbey. Journal Droit et Société.

* Professor Doutor da Faculdade de Direito da Universidade de São Paulo e da Faculdade de Direito da Universidade Presbiteriana Mackenzie. 
Introdução

Em janeiro de 2019, por ocasião das comemorações relativas à publicação do centésimo número da revista Droit et Société, a École Normale Supérieure ParisSaclay promoveu uma jornada de estudos com o propósito de discutir os aportes desse importante periódico para a difusão da pesquisa interdisciplinar no "campo dos estudos sociojurídicos". ${ }^{1}$ Conjugando os eventos "Écrire et publier en sociologie du droit" e "Droit et société en débat: regards internationaux sur les Legal Consciousness Studies. Quelles perspectives pour Droit et Société?", a referida jornada congregou autores das mais variadas proveniências com a finalidade de promover uma reflexão relativa à produção científica na área e os rumos do periódico fundado em 1985 por André-Jean Arnaud, Jacques Commaille e Jean-François Perrin. ${ }^{2}$

Cabe, assim, aludir brevemente às diretrizes que, desde a origem, orientaram a linha editorial da revista Droit et Société. Quanto a esse aspecto, vale notar que o editorial do primeiro número da revista, redigido por André-Jean Arnaud, enfatizava a "abertura ao exterior" e a "interdisciplinaridade" como os dois aspectos fundamentais que deveriam caracterizá-la. ${ }^{3}$ Dois anos depois, em 1987, ao refletirem sobre a pretensão de articulação entre teoria do direito e sociologia jurídica, Arnaud e Jacques Commaille reafirmavam o caráter central da interdisciplinaridade no projeto editorial da revista. ${ }^{4}$ Em 1999, o editorial do número 42/43, ao fazer um balanço dos primeiros quinze anos de circulação da revista, ratifica, de modo bastante enfático, o seu caráter antidogmático, interdisciplinar e internacional. ${ }^{5}$ Em 2015, por ocasião da publicação da edição comemorativa de seus trinta

1 Segundo Arnaud e Fariñas Dulce (1998), os estudos sociojurídicos seriam expressão de um campo de pesquisa interdisciplinar. A respeito, ver: Villas Bôas Filho (2018a, 2018c e 2019b).

2 Fundada por André-Jean Arnaud, Jacques Commaille e Jean-François Perrin, em 1985, e inspirando-se na Revue internationale de la théorie du droit, fundada, em 1926, por Hans Kelsen, Léon Duguit e Franz Weyr, a revista Droit et Société tem por finalidade promover a difusão da pesquisa desenvolvida no âmbito da teoria do direito e da sociologia jurídica. Desse modo, desde a sua origem, ela designa-se Droit et Société. Revue Internationale de Théorie du Droit et de Sociologie Juridique. A respeito, ver, especialmente: Arnaud (1985), Arnaud e Commaille (1987), Commaille (1992) e Arnaud, Commaille e Ost (1999). Sobre essa questão e, principalmente, sobre as tensões entre a perspectiva da teoria do direito e da sociologia jurídica no bojo do projeto editorial da revista, ver o excelente artigo de Condé (2015). Acerca da gênese da revista e das afinidades e distanciamentos dela relativamente à Revue Internationale de la Théorie du Droit, ver: Perrin (2019). A respeito, ver também: Capeller (1991 e 2019) e García Villegas (2015).

3 Assim, Arnaud (1985, p. 6) ressaltava que "la revue sera donc, avant tout, tournée vers l'extérieur" e "nous nous efforcerons de 'couvrir' systématiquement les diverses manifestations scientifiques [...]". Conforme ressaltam Raimbault e Simoulin (2019), essa perspectiva interdisciplinar também se expressa nas coleções Droit et Société.

4 Na apresentação do n. 7 da revista, Arnaud e Commaille (1987, p. 324) salientavam que "c'est là que théoriciens et sociologues du droit peuvent collaborer. Encore l'existence d'un dialogue fructueux entre eux suppose-t-elle l'élaboration commune d'une stratégie de dialogue, qui est l'un des buts primordiaux de cette revue".

5 No referido editorial, Arnaud, Commaille e Ost (1999, p. 231) afirmam que “C'est ainsi que, partis d'une 
anos de existência, o editorial do número 91 - em estreita consonância com os anteriores e, em especial, com o de 1987 - também sublinha a relevância da interdisciplinaridade no horizonte de seu escopo editorial. ${ }^{6}$

A vinculação às balizas fundamentais que, desde sua origem, a caracterizam - antidogmatismo, interdisciplinaridade e internacionalidade - expressam-se, em primeiro lugar, na escolha de diversos autores cujas obras foram analisadas nos sucessivos números da revista. Assim, além de contemplar expressivos autores franceses como Pierre Bourdieu (n. 32, 1996, e n. 56-57, 2004) e Michel Villey (n. 71, 2009), os dossiês da revista também contemplaram as obras de autores como Ronald Dworkin (n. 1, 1985); Niklas Luhmann (n. 11-12, 1989, e n. 47, 2001); Alf Ross (n. 50, 2002); Axel Honneth (n. 78, 2011); Marc Galanter (n. 85, 2013); Georges Gurvitch (n. 94, 2016) e Susan Silbey (n. 100, 2018). Por outro lado, o caráter interdisciplinar e crítico da revista também se revela na escolha das temáticas que constituíram objeto de seus dossiês. Alguns exemplos são muito significativos a esse respeito: Le droit en action et en contexte. Ethnométhodologie et analyse de conversation dans la recherche juridique (n. 48, 2001); La gouvernance: une approche transdisciplinaire (n. 54, 2003); Savoirs académiques, savoirs pour l'action? (n. 60, 2005); Quelles méthodes pour la sociologie du droit et de la justice? (n. 69-70, 2008); Sciences sociales, droit et science du droit: le regard des juristes (n. 75, 2010); Rationalité juridique vs rationalité managériale? (n. 84, 2013); Politique et droit de l'État en perspectives (n. 92, 2016).

O editorial e o dossiê que integram o número 100 da revista Droit et Société explicitam e, inclusive, acentuam tanto o seu caráter interdisciplinar e crítico quanto sua pretensão de congregar a pesquisa internacional. Reforçam, nesse sentido, o compromisso com as balizas que, desde a origem, nortearam a revista. No tocante a esse aspecto, vale lembrar que o dossiê do primeiro número da revista Droit et Société, dedicado à obra de Ronald Dworkin, teve por foco, portanto, a teoria do direito e a abordava mediante a abertura a um autor anglófono. O centésimo número da revista, também preocupado em preservar o diálogo internacional ao qual a revista desde a sua origem se vocacionou,

posture résolument antidogmatique, interdisciplinaire et internationale, sur les traces déjà difficiles à concilier d'un Kelsen et d'un Le Fur, nous souhaitions, dès le premier éditorial, faire preuve de souplesse, forger un outil de travail, matérialiser un réseau d'échanges critique, non sectaire, contrôlé par les seuls impératifs de la rigueur intellectuelle, centré sur l'objet 'droit' dans une perspective de 'dévoilement', c'est-à-dire de 'mise en évidence de ses conditions d'émergence et de ses effets par des procédures qui ne se fondent que sur des prémisses hypothétiques et non pas des hypostases' (n. 1, 1985)". Como se verá adiante, essa pretensão de "desvelamento" também perpassa a "sociologia política do direito". A respeito, ver: Commaille (1994).

6 A respeito, Arnaud e Commaille (2015, p. 455) ressaltam que, ao longo das três décadas de sua existência, a revista, entre outras coisas, teria se caracterizado por "un souci permanent de dialogue entre des communautés intellectuelles, le droit d'une part, les sciences sociales d'autre part, dont les relations ont souvent souffert d'indifférence sinon d'hostilité l'une envers l'autre". 
tem por objeto de seu dossiê a obra de Susan Silbey, autora central no âmbito dos Legal Consciousness Studies. Assim, se comparado ao dossiê do primeiro número da revista, este último, além de um caráter mais direcionado à sociologia do que à teoria do direito, consigna um contorno ainda mais marcadamente interdisciplinar. ${ }^{7}$

Escrito por Pierre Brunet e Laurence Dumoulin, o editorial do centésimo número da revista Droit et Société procura enfatizar as diretrizes - internacionalidade, crítica e interdisciplinaridade - que, desde a origem, a caracterizaram. ${ }^{8}$ Nesse sentido, os autores ressaltam que a escolha da obra de Susan Silbey como objeto do dossiê dessa edição comemorativa não é ocasional, pois, em primeiro lugar, evidencia a vocação internacional de uma revista francesa ao que se passa em um contexto acadêmico e intelectual distinto daquele no qual está inscrita. ${ }^{9}$ Ademais, os chamados Legal Consciousness Studies são resolutamente críticos no que tange às representações convencionais, de viés positivista, acerca do direito. ${ }^{10}$ Contudo, e é esse o ponto a ser priorizado neste artigo, a obra de Susan Silbey também se configura pelo seu contorno interdisciplinar.

Portanto, com o intuito de sublinhar o caráter interdisciplinar dos Legal Consciousness Studies, de modo a apontar sua afinidade com uma das diretrizes fundamentais que norteiam a linha editorial da revista Droit et Société, o presente artigo fará,

7 É possível afirmar que isso decorre do perfil das obras que constituem o objeto de um e de outro desses dois dossiês. Quando comparadas, nota-se que os Legal Consciousness Studies de Susan Silbey têm um caráter bem mais interdisciplinar do que a teoria jurídica de Ronald Dworkin.

8 A respeito, Brunet e Dumoulin (2018, p. 540), fazendo alusão ao dossiê da centésima edição da revista, ressaltam que, "comme on pourra le lire, le dossier s'inscrit parfaitement dans cette posture résolument antidogmatique, interdisciplinaire et internationale qu'appelaient de leurs vœux les fondateurs de la revue". Assim, referindo-se ao editorial do número 42-43, de 1999, escrito por André-Jean Arnaud, Jacques Commaille e François Ost, Brunet e Dumoulin (2018, p. 540) salientam também que o centésimo número da revista "prolonge, à sa façon, l'entreprise commencée il y a plus de trente ans et qui visait à 'forger un réseau d'échanges critique, non sectaire, contrôlé par les seuls impératifs de la rigueur intellectuelle, centré sur l'objet 'droit' dans une perspective de 'dévoilement'”.

9 É bem verdade que essa abertura internacional se direciona à produção acadêmica hegemônica que, enquanto tal, se impõe em escala mundial. De todo modo, ao longo de sua história, a revista Droit et Société não foi indiferente à produção intelectual de contextos acadêmicos subalternos. No que tange à América Latina, o dossiê do número 22 da revista, publicado em 1992, é particularmente significativo. Congregando autores como Wanda Capeller, Debra Evenson, W. Gordon West, Fernando Rojas Hurtado, Eliane Botelho Junqueira e Luciano Oliveira. Sobre esse ponto, cumpre notar que André-Jean Arnaud, um dos fundadores da revista, sempre se mostrou sensível à questão das assimetrias de poder no bojo da produção acadêmica, em especial da sociologia jurídica. A respeito, ver, especialmente, Arnaud (1981 e 1998) e Villas Bôas Filho (2017b).

10 Brunet e Dumoulin (2018) também associam os Legal Consciousness Studies à pretensão de "desvelamento" que, desde do Editorial do número 20-21, de 1992, passou a figurar também como uma das metas da revista. Assim, referindo-se a essa expressiva corrente da sociologia jurídica anglófona, Brunet e Dumoulin (2018, p. 540) ressaltam que "il s'agit de dévoiler tout autant la multiplicité que la complexité des rapports que les individus peuvent entretenir non plus seulement avec le droit mais avec la légalité. Et dévoiler aussi les enjeux sociaux et politiques auxquels le droit prend toujours sa part mais que tendent à masquer les approches formalistes ou dogmatiques". 
em primeiro lugar, uma breve alusão à proposta de André-Jean Arnaud de desenvolvimento dos estudos sociojurídicos como um campo de pesquisa interdisciplinar e à "sociologia política do direito" de Jacques Commaille. Essa menção se faz particularmente importante em virtude da ascendência intelectual desses dois autores sobre a linha editorial da revista Droit et Société. Em seguida, será realizada uma despretensiosa incursão pela obra de Susan Silbey, cujo intuito fundamental é destacar o seu contorno interdisciplinar, pois isso permite explicitar uma das razões de sua escolha como objeto do dossiê do centésimo número da referida publicação. A partir daí, será feita uma breve referência à recepção dos Legal Consciousness Studies e, em particular, da obra de Susan Silbey, no âmbito dos estudos sociojurídicos na França, com especial ênfase nas afinidades existentes entre eles e a "sociologia política do direito" de Jacques Commaille. ${ }^{11}$ Por fim, à guisa de conclusão, serão sintetizadas as questões examinadas no artigo.

1. Os estudos sociojurídicos como campo interdisciplinar: um breve excurso pelas obras de André-Jean Arnaud e de Jacques Commaille

André-Jean Arnaud, Jacques Commaille e Jean-François Perrin foram fundadores da revista Droit et Société. Entretanto, em 1992, o último dos três autores citados, por solicitação própria, desvinculou-se do Comitê Editorial da revista. AndréJean Arnaud e Jacques Commaille remanesceram como membros fundadores da revista e, durante décadas, como as principais figuras de seu organograma. ${ }^{12}$ Logo, a digressão que será feita a seguir, ao ressaltar a importância por eles atribuída à interdisciplinaridade, visa explicitar a centralidade dessa questão no âmbito da publicação por eles concebida. Não se trata aqui, obviamente, de empreender uma análise sistemática desse tema na obra desses dois autores, mas apenas de apontar o modo pelo qual um e outro a concebem, pois, a partir daí, é possível mapear os seus reflexos no projeto editorial da prestigiosa publicação por eles criada e dirigida. ${ }^{13}$

A proposta de constituição de um "carrefour interdisciplinaire" para o estudo do direito foi formulada originalmente por Arnaud (1988) e consiste na pretensão de promover a pesquisa interdisciplinar mediante a construção de uma linguagem

\footnotetext{
11 A respeito, ver: García Villegas (2015).

12 Vale notar que, em 1992, Jean-François Perrin se desligou do Comitê Editorial da revista Droit e Société, passando a figurar, por solicitação própria, apenas como correspondente na Suíça. A respeito, ver a carta de desligamento que integra o número 22 da revista. André-Jean Arnaud permaneceu no Comitê Editorial até o seu falecimento, em dezembro de 2015. Atualmente, o referido Comitê é composto por Jacques Commaille, único membro da composição inicial, por François Ost e por Philippe Raimbault.

13 Note-se que é justamente o Editorial do número 42/43, de 1999, escrito por André-Jean Arnaud, Jacques Commaille e François Ost, que, ao realizar um balanço dos quinze anos da revista, reforça explicitamente a "postura resolutamente antidogmática, interdisciplinar e internacional" que a caracterizaria.
} 
comum, sobre um mesmo objeto e com um propósito também comum. ${ }^{14}$ Em seguida, essa questão é objeto de uma expressiva análise em um artigo publicado no número 20-21 da revista Droit et Société em que o autor propugna a construção de um campo de pesquisa interdisciplinar e identifica os "estudos sociojurídicos" como o seu âmbito próprio de desenvolvimento. Para Arnaud (1992), além de constituírem o campo privilegiado para a pesquisa interdisciplinar, os "estudos sociojurídicos" possibilitariam o desenvolvimento de uma pesquisa distinta da pura teorização e do dogmatismo estéril. ${ }^{15}$

A respeito, Arnaud (1994) sustenta que a expressão “estudos sociojurídicos” englobaria, genericamente, o conjunto dos pesquisadores interessados em uma abordagem social do direito. ${ }^{16}$ Os "estudos sociojurídicos" constituiriam, assim, um tipo de sociologia jurídica renovada, na qual as dimensões econômica e política seriam adicionadas às reivindicações realistas dos primeiros sociólogos jurídicos. Contudo, segundo o autor, dessa abordagem social do direito resultaria uma ruptura epistemológica. Para explicitar o que nela está implicado, Arnaud (1992) contrapõe o que designa de "epistemologia positivista" (consistente na atitude de técnicos a serviço de estratégias cujos propósitos lhes escapam) e de "epistemologia constitutiva" (que, em seu entendimento, seria suscetível de franquear acesso à realidade social com a qual os juristas se confrontam). Sem adentrar na análise que Arnaud (1992) faz desses dois tipos de epistemologia, cumpre notar que, em seu entendimento, somente o segundo deles possibilitaria o desenvolvimento de uma abordagem verdadeiramente interdisciplinar do direito. ${ }^{17}$

No entanto, conforme sustenta Arnaud (1992), a interdisciplinaridade não seria algo simples de implementar. O maior problema à sua realização consistiria,

14 Referindo-se a esse projeto, Arnaud (1988, p. 7; 1998, p. 77) afirma que se trata de "l'élaboration des grandes lignes d'une Théorie du droit et de la société qui permette aux juristes et aux chercheurs en sciences sociales de travailler avec un langage commun sur un objet commun et dans un but commun". Arnaud (1991) procurou introduzir essa questão na discussão brasileira mediante sua incorporação a uma coletânea de artigos que publicou em português. Sobre a questão da interdisciplinaridade, ver também Arnaud (2013). Por fim, vale notar que a obra de Arnaud se afigura como um "modelo de interdisciplinaridade", tal como sublinha Ost (2016), ou como expressão paradigmática do que Commaille (2016) designa de "pesquisa de complementaridades".

15 Segundo Arnaud (1992, p. 18), "la discipline par où les chercheurs entendent précisément échapper tant à la pure théorisation qu'au dogmatisme stérile, se trouve aux confins de la politique, de la psychologie, de la sociologie et du Droit et se nomme, selon les lieux et les écoles, sociologie du Droit, sociologie juridique, Socio-legal studies, Law and Society studies, Law in context". No mesmo sentido, ver: Arnaud (2013) e Arnaud e Fariñas Dulce (1998). Aliás, García Villegas (2015, p. 288) ressalta que "la revue conçoit ainsi la sociologie du droit comme une "spécialisation interdisciplinaire"'.

16 Note-se que Brunet e Dumoulin (2018) também enfatizam esse aspecto na justificativa de escolha da obra de Susan Silbey como objeto do dossiê do centésimo número da revista.

17 Segundo Arnaud (1992, p. 26), “au-delà des partitions disciplinaires, il devenait urgent de trouver de nouveaux fondements épistémologiques à une science dont l'objet ne pouvait être déterminé avec précision selon les données de l'épistémologie positiviste". O autor procura mapear o delineamento desses novos fundamentos epistemológicos em autores como Gaston Bachelard, Jean Piaget, Karl Popper e Thomas Kuhn, Jürgen Habermas, Michel Foucault e Pierre Bourdieu. 
segundo o autor, na dificuldade que os pesquisadores egressos de campos disciplinares distintos teriam em chegar a um acordo acerca do que é o Direito, uma vez que cada analista tende a constituí-lo segundo os cânones próprios à sua formação disciplinar. Daí, aliás, o seu diagnóstico nada alentador de que, no contexto atual, mais do que interdisciplinaridade, haveria uma espécie de "cacofonia" (ARNAUD, 1992, p. 25). ${ }^{18}$ No mesmo sentido, Rouland (2018, p. 21), a partir de uma abordagem franco-brasileira, afirma que "l'interdisciplinarité n'est bien souvent qu'un slogan".

Diante disso, André-Jean Arnaud preocupou-se intensamente com o desenvolvimento dos estudos sociojurídicos, concebendo-os como um "campo de pesquisa interdisciplinar". ${ }^{19}$ Trata-se de um tema de grande importância no bojo de sua obra que, em diversos momentos, consigna uma reflexão acerca das condições de possibilidade de uma perspectiva que, congregando diversos pontos de vista, pudesse ser crítica e antidogmática. Assim, Arnaud e Fariñas Dulce (1998), renunciando a estruturar uma disciplina como local de desenvolvimento da pesquisa interdisciplinar, preferem se referir a um "campo de estudos" no qual poderiam interagir, de forma equilibrada, diversas concepções acerca do direito. ${ }^{20}$ Por conseguinte, tornar-se-ia possível, nessa proposta, a conjugação equilibrada dos mais diversos ângulos de abordagem da regulação jurídica. ${ }^{21}$

Analogamente, toda a empreitada intelectual de Jacques Commaille também se caracteriza pela assunção de uma perspectiva interdisciplinar. ${ }^{22}$ Nesse particular, a sua "sociologia política do direito", mantendo clara afinidade com a linha editorial da revista Droit et Société, constitui-se como expressão lapidar de uma compreensão interdisciplinar da regulação jurídica. ${ }^{23}$ Trata-se de uma característica que se expressa claramente

18 Vale notar que essa situação, identificada pelo autor no contexto europeu de há mais de um quarto de século, ainda grassa no Brasil de hoje, onde, quando existente, o que se observa é, como regra, uma "interdisciplinaridade de pacotilha". Sobre o caráter muitas vezes frustrante da colaboração interdisciplinar nos estudos jurídicos, ver: Campilongo (2000). A respeito, ver: Villas Bôas Filho (2018a e 2019b).

19 A respeito, ver, especialmente: Arnaud e Fariñas Dulce (1998). É possível observar claramente a implementação dessa pesquisa interdisciplinar na análise feita por Arnaud (2014) acerca da governança. Sobre essa temática no pensamento de Arnaud, ver: Ferreira e Pedroso (2019), Ortiz (2019) e Villas Bôas Filho (2016a, 2016b, 2018b e 2019a).

20 Referindo-se à possibilidade de desenvolvimento de pesquisas interdisciplinares, Arnaud e Fariñas Dulce (1998, p. 162-163) afirmam o seguinte: “oublions d'en faire une discipline et parlons provisoirement d'un champ d'étude. Dans ce champ, interviendront des regards croisés".

21 Ao conceberem os estudos sociojurídicos como um campo de pesquisa interdisciplinar, Arnaud e Fariñas Dulce (1998, p. 162) afirmam que "qui dit collaboration dit équilibre". Analogamente, Bailleux e Ost (2013, p. 43) ressaltam que "la pratique interdisciplinaire est toujours menacée d'opérer au service unique d'une discipline qui se place en position centrale, posant les questions et suggérant les réponses à des disciplines vouées alors à 'l'ancillarité'”'.

22 Para uma análise da interdisciplinaridade a partir da obra Jalons pour une théorie critique du droit de François Ost e Michel Van de Kerchove, ver: Commaille (1988). Acerca dessa questão, ver também: Dumont e Bailleux (2010).

23 Acerca da "sociologia política do direito", ver, especialmente: Commaille (1994 e 2013b), Commaille e Duran (2009), Caillosse (2011), Corten (1998) e Villas Bôas Filho (2015a). 
no delineamento que lhe é dado por Commaille (1994) ${ }^{24}$ e reafirmada enfaticamente em Commaille (2010, 2015, 2016 e 2019). Não cabe aqui realizar uma digressão mais pormenorizada acerca dessa questão, mas apenas apontar a sua importância no delineamento da obra desse autor que, tal como André-Jean Arnaud, teve, historicamente, uma grande ascendência sobre a linha editorial da revista Droit et Société.

Para os propósitos deste artigo, basta notar que, rejeitando clivagens artificiais no âmbito das ciências sociais, a "sociologia política do direito" adota uma clara perspectiva interdisciplinar. Remetendo a autores como Fernand Braudel e Immanuel Wallerstein, com os quais mantém evidente relação de afinidade, Commaille (2010) enfatiza que a manutenção de fronteiras entre as ciências sociais hoje decorreria mais de razões institucionais ou corporativas do que propriamente de razões cognitivas. ${ }^{25}$ Assim, assumindo uma pretensão interdisciplinar, a "sociologia política do direito" elege a questão do poder como objeto privilegiado de estudo e, fazendo-o, identifica no direito um instrumento fundamental de "revelação" dos processos constitutivos e de funcionamento do poder, uma vez que, baseando-se em autores com Michel Troper e Pierre Bourdieu, reconhece a "forma jurídica" como "a estrutura do discurso pelo qual se exprime o poder" e como o instrumento que institucionalizaria a "manutenção da ordem social e política". ${ }^{26}$ Commaille (2015) reafirma enfaticamente a pretensão de interdisciplinaridade de sua perspectiva que, em suas palavras, poderia ser considerada uma "pesquisa de complementaridades". ${ }^{27}$ Assim, retomando e aprofundando análises anteriores, Commaille (2015) procura mostrar que o direito consiste em um extraordinário revelador das transformações dos modos de regulação social e política. ${ }^{28}$ Nesse sentido, procurando inscrever-se na tradição dos fundadores da sociologia, o autor reitera que o direito poderia ser enfocado como um revelador das mutações sociais e políticas

${ }_{24}$ Assim, Commaille (1994, p. 35) afirma que "l'appréhension du droit comme fait social renvoie à une activité intellectuelle relevant des sciences sociales, plus particulièrement de la sociologie juridique, où la signification du droit est recherchée dans l'interaction entre les manifestations du social et les expressions juridiques correspondantes, non seulement dans leurs fonctions réelles mais aussi éventuellement symboliques". Aliás, por esse motivo, Corten (1998, p. 360) observa, com razão, que "il est non seulement possible mais indispensable de passer par d'autres disciplines pour réaliser une étude de sociologie du droit".

25 A respeito, ver também: Commaille e Duran (2009) e Villas Bôas Filho (2015a).

26 No que concerne à noção de campo jurídico, ver, especialmente: Bourdieu (1986a; 1986b; 1991; 1993; 2012; 2015 e 2016), García Villegas (2004), Guibentif (2010), Roussel (2004), Sckell (2016) e Sueur (2013).

27 A respeito, Commaille $(2015$, p. 24), referindo-se à sua trajetória, declara-se "de plus en plus militant d'une pluri et même d'une interdisciplinarité [...]". Propõe, assim, o que designa de "recherche de complémentarité" (COMMAILLE, 2016, p. 12). Sobre a interdisciplinaridade na obra de Arnaud, ver: Villas Bôas Filho (2017b).

28 A respeito, ver: Commaille (1994, 2010 e 2016) e Commaille e Duran (2009). 
contemporâneas. ${ }^{29}$ Para levar a efeito essa empreitada teórica, Commaille (1994, 2015 e 2016) assume uma perspectiva resolutamente interdisciplinar e propõe uma redefinição da relação entre a ciência jurídica e as ciências sociais de modo a superar a tendência de desqualificação recíproca que se construiu entre esses âmbitos. ${ }^{30}$

Essa breve incursão pela centralidade que André-Jean Arnaud e Jacques Commaille atribuem à interdisciplinaridade no bojo de suas respectivas obras faz-se importante, no âmbito deste artigo, em virtude da ascendência de ambos no delineamento da linha editorial da revista Droit et Société. A respeito, é preciso notar que esses dois autores foram os fundadores da revista e remanesceram como membros de seu Comitê Diretor durante décadas. ${ }^{31}$ Assim, a alusão à importância assumida pela interdisciplinaridade na tessitura de suas respectivas obras ajuda a compreender a centralidade dessa questão no perfil editorial da revista por eles concebida e, ao longo dos anos, dirigida. Diante disso, o dossiê intitulado "After Legal Consciousness Studies: dialogues transatlantiques et transdisciplinaires" expressa, com toda a evidência, a consagração das balizas editoriais, desde a origem, que pautaram a revista Droit et Société.

\section{O caráter interdisciplinar da obra de Susan Silbey e dos Legal Consciousness} Studies

O presente artigo não tem a pretensão de analisar a obra de Susan Silbey que, como se sabe, ocupa uma posição central no âmbito dos Legal Consciousness Studies. Uma empreitada dessa magnitude seria incompatível como as dimensões e os propósitos deste estudo, cujo intuito consiste apenas em sublinhar um aspecto da obra da autora americana - a interdisciplinaridade - para, a partir daí, evidenciar um dos motivos essenciais de sua escolha como tema do centésimo número da revista Droit et Société. Trata-se, portanto, de uma abordagem bastante pontual e despretensiosa que, seguindo, Wyvekens (2018), se abstém de “entrer de plain-pied dans l'œuvre” de Susan Silbey, restringindo-se a indicar o seu caráter interdisciplinar. Por conseguinte, será feita a seguir uma breve alusão à gênese dos Legal Consciousness Studies e à complexa trama de

29 Cf. Commaille (2015 e 2016).

30 Segundo Commaille (2016, p. 2), “il n'est pas indifférent de se rappeler que ces rapports entre la sociologie, les sciences sociales et le droit sont d'abord des rapports de rejet. En France, la sociologie a disqualifié le droit comme objet de recherche au motif que celui-ci n'était que le 'miroir' et le simple instrument de gestion de rapports sociaux, déterminés par les rapports économiques qui sont ceux de l'économie capitaliste. La science politique a superbement ignoré le droit, masquant par une transposition dans un argumentaire relevant du registre épistémologique ce qui tenait d'abord à un conflit de nature institutionnelle avec les Facultés de droit".

31 André-Jean Arnaud figurou como membro do Comitê Diretor da revista até seu falecimento e Jacques Commaille ainda nele remanesce com François Ost e Philippe Raimbault. 
conceitos que embasa o conceito de "legalidade" (legality), tal como desenvolvido por Susan Silbey e Patricia Ewick.

Com o objetivo de examinar a gênese dos Legal Consciousness Studies, Wyvekens (2018) alude à emergência da sociologia do direito nos EUA, na década de 1930, período em que, segundo ela, os professores de direito, com o propósito de aprimorar a efetividade do sistema jurídico, teriam procurado aproveitar os aportes das ciências sociais, especialmente mediante a utilização de seus métodos empíricos. Nesse sentido, a partir dessa abertura às ciências sociais, a Sociological Jurisprudence e o Legal Realism teriam procurado, de um lado, tornar as decisões jurídicas mais previsíveis e, de outro, reformar um sistema considerado excessivamente dogmático e formalista. ${ }^{32}$

Segundo Wyvekens (2018), foi na esteira desse movimento que, em 1964, fundou-se a Law and Society Association com a pretensão de modificar, em profundidade, a formação jurídica por meio da importação dos instrumentos e dos métodos das ciências sociais para as Faculdades de Direito. Contudo, conforme a autora, em virtude de seu caráter instrumental, a Law and Society Association teria remanescido em uma posição ancilar no campo universitário norte-americano, tanto nas Faculdades de Direito como nas de Ciências Sociais. No fim da década de 1970, teria ocorrido a emergência dos Critical Legal Studies, movimento "heterogêneo" e "efêmero" com o propósito precípuo de analisar como o direito contribui para forjar as maneiras pelas quais o mundo social é percebido e construído. ${ }^{33}$ Conforme ressaltam Silbey (2018) e Wyvekens (2018), os Critical Legal Studies teriam contribuído, especialmente a partir da década de 1990, para um estreitamento dos laços entre juristas e cientistas sociais. ${ }^{34}$

Segundo Wyvekens (2018), o Amherst Seminar on Legal Ideology and Legal Process, constituído em 1982 ao redor de Susan Silbey, Austin Sarat e Christine Harrington, estaria inscrito nessa perspectiva, demarcando-se, entretanto, os Critical Legal Studies em virtude de sua dimensão essencialmente empírica e de um deslocamento em direção à sociologia qualitativa e, inclusive, à antropologia. ${ }^{35}$ Logo, ao lado de sua dimensão resolutamente crítica, os Legal Consciousness Studies teriam como marca constitutiva o seu contorno interdisciplinar. Nesse sentido, Susan Silbey - figura central no

32 Sobre a Sociological Jurisprudence e o Legal Realism, ver, especialmente: Hunt (1978).

33 Nesse particular, a análise de Wyvekens (2018) funda-se nas de Antoine Vauchez e Jérôme Pélisse. Segundo Silbey (2018, p. 694), "the rise of CLS within law schools resurrected from de aborted project of legal realism the aspect devoted to deconstructing legal doctrine to reveal its irrational and illogical claims".

34 A respeito, Silbey (2018, p. 694) ressalta que "it was not until the late 1990s following the flourishing of Critical Legal Studies (CLS) in the 1980s that social scientists were actively welcomed into the law schools".

35 A respeito, ver: Delpeuch, Dumoulin e Galembert (2014) e García Villegas (2015). 
âmbito desses estudos - afirma que "the study of legal consciousness developed directly from the various contributions of the several disciplines" (SILBEY, 2018, p. 697). ${ }^{36}$

\section{Quadro 1}

\section{Referências incontornáveis no campo dos Legal Consciousness Studies}

\begin{tabular}{|c|c|}
\hline Título da referência & Razão da importância \\
\hline $\begin{array}{l}\text { SARAT, Austin. The law is "all over": power, } \\
\text { resistance and the legal consciousness of the } \\
\text { welfare poor. Yale Journal of Law and Humanities, } \\
\text { New Haven, v. } 2 \text {, n. } 2 \text {, p. } 343-379,1990 \text {. }\end{array}$ & $\begin{array}{l}\text { Trata-se de um dos artigos de fundação dos Legal } \\
\text { Consciousness Studies. }\end{array}$ \\
\hline $\begin{array}{l}\text { MERRY, Sally Engle. Getting justice and getting } \\
\text { even: legal consciousness among working-class } \\
\text { Americans. Chicago: University of Chicago Press, } \\
1990 .\end{array}$ & $\begin{array}{l}\text { Trata-se de um dos artigos de fundação dos Legal } \\
\text { Consciousness Studies. }\end{array}$ \\
\hline $\begin{array}{l}\text { MCCANN, Michael. W. Rights at work: pay equity } \\
\text { reform and the politics of legal mobilization. } \\
\text { Chicago: University of Chicago Press, } 1994 \text {. }\end{array}$ & $\begin{array}{l}\text { Obra central no campo do Law and Society Studies } \\
\text { que articula a sociologia dos movimentos sociais } \\
\text { com os Legal Consciousness Studies. }\end{array}$ \\
\hline $\begin{array}{l}\text { EWICK, Patricia; SILBEY, Susan S. The common } \\
\text { place of law: stories from everyday life. Chicago: } \\
\text { University of Chicago Press, } 1998 .\end{array}$ & Obra seminal dos Legal Consciousness Studies. \\
\hline $\begin{array}{l}\text { ENGEL, M. David; MUNGER, Frank W. Rights } \\
\text { of inclusion: law and identity in the life stories of } \\
\text { Americans with disabilities. Chicago: University } \\
\text { of Chicago Press, } 2003 \text {. }\end{array}$ & $\begin{array}{l}\text { Obra central no bojo dos Legal Consciousness } \\
\text { Studies. }\end{array}$ \\
\hline $\begin{array}{l}\text { SILBEY, Susan S. After legal consciousness. } \\
\text { Annual Law Review of Law and Social Science, v. } \\
\text { 1, p. 323-368, } 2005 \text {. }\end{array}$ & $\begin{array}{l}\text { Trata-se de artigo que consigna uma avaliação } \\
\text { crítica de Susan Silbey acerca dos usos do } \\
\text { conceito de Legal Consciousness no âmbito da } \\
\text { sociologia norte-americana. }\end{array}$ \\
\hline $\begin{array}{l}\text { NIELSEN, Laura Beth; FLEURY-STEINER, } \\
\text { Benjamin (ed.). The new civil rights research: } \\
\text { a constitutive approach. Aldershot, UK and } \\
\text { Burlington, VT: Ashgate Publishing, } 2006 .\end{array}$ & $\begin{array}{l}\text { Trata-se de obra que reúne as comunicações } \\
\text { apresentadas na rede Legal Consciousness Studies. }\end{array}$ \\
\hline $\begin{array}{l}\text { SILBEY, Susan S. Studying legal consciousness: } \\
\text { building institutional theory form micro data. } \\
\text { Droit et Société, Cachan, n. } 100 \text {, p. } 685-731,2018 .\end{array}$ & $\begin{array}{l}\text { Trata-se de artigo em que a autora, respondendo a } \\
\text { interlocutores franceses, explicita as bases de sua } \\
\text { obra. }\end{array}$ \\
\hline
\end{tabular}

Adaptado de Chappe, Pélisse e Egea (2018, p. 669)

36 Referindo-se aos Legal Consciousness Studies, Silbey (2018, p. 697) enfatiza essa característica ao afirmar que "the different disciplinary tools (e.g. concepts and methods) became avaiable to all o fus - a focus on the state from political science, organizational process form sociology, culture from anthropology. From persistent interaction, we began to see both limits in what was taken for granted in our respective disciplines while forging a synthesis across them”. A respeito, ver também Silbey (2005). 
A reprodução desse quadro adaptado visa ressaltar a importância da obra de Susan Silbey em meio aos Legal Consciousness Studies. É possível afirmar que, pelo menos desde a publicação, em 1998, do livro The common place of law: stories from everyday life, Susan Silbey adquiriu evidente centralidade no âmbito dos Legal Consciousness Studies. ${ }^{37}$ Esse complexo estudo, elaborado em coautoria com Patricia Ewick, é, ademais, uma expressão clara do perfil interdisciplinar que os caracteriza. Trata-se, aliás, de um aspecto insistentemente sublinhado por Silbey (2005 e 2018) acerca de sua própria perspectiva teórica. Com o intuito de explicitar ainda mais essa vocação interdisciplinar na obra da autora, será feita, a seguir, uma breve menção ao conceito de "legalidade" (legality) por ela proposto, uma vez que este congrega aportes provenientes de diversas disciplinas. Não se trata, evidentemente, de um exame mais detido desse complexo "construto analítico", tal como a autora o designa. ${ }^{38} \mathrm{O}$ que se visa aqui é apenas sublinhar o quanto, na própria tessitura analítico-conceitual, de sua obra é fundada na interdisciplinaridade.

A "legalidade" como "construto analítico" ocupa uma posição central na análise que Ewick e Silbey (1998) fazem sobre a "consciência do direito". A respeito, Silbey (2005) ressalta que esta última consistiria na participação no processo de construção da "legalidade". ${ }^{39}$ De fato, Ewick e Silbey (1998) utilizam o termo "legalidade" para se referirem às significações, às fontes de autoridade e às práticas culturais reconhecidas correntemente como jurídicas, independentemente de quem as empregue ou para quais propósitos. Por meio desse "construto analítico", as autoras procuram diferenciar o âmbito de suas pesquisas das manifestações institucionais da "legalidade" presentes no direito positivo, na profissão jurídica, nas formas, atos e processos. ${ }^{40}$ Para tanto, definem a "legalidade" como "componente estrutural da sociedade" que se constrói pautada

37 Vale, entretanto, notar que, conforme Silbey (2018, p. 699), "contemporary studies of legal consciousness follow divergent paths: one stream relying on the actor as the unit of analysis and the explanation, the other focusing on the institution, synthesizing across the diverse empirical accounts to model the structure of legality".

38 Silbey (2005, p. 347) qualifica a "legalidade" como um "termo analítico" (analytic term) e como "construto analítico" (analytic construct). Não a designa, portanto, de "noção" ou de "conceito". Essas designações são utilizadas pela autora quando esta se refere à "consciência do direito", à "cultura" ou à "hegemonia". Nesses casos, Silbey (2005) adota o termo "conceito" (concept) e as expressões "conceito teórico" (theoretical concept) e "conceito analítico" (analytical concept). Sem desconsiderar essa distinção na obra da autora, este artigo referir-se-á, genericamente, à "legalidade" também como um conceito. Note-se que Silbey (2018, p. 711) concerne a "direito" (law) e "legalidade" (legality) como "conceitos".

39 Referindo-se, em retrospecto, ao livro The common place of law: stories from everyday life, Silbey (2005, p. 347) destaca que "Ewick and Silbey produced an account not of persons but of what they called legality, defining legal consciousness as the participation in this process of constructing legality".

40 Aliás, o mesmo ocorre com a orientação teórica que embasa essas pesquisas. Como visto, os Legal Consciousness Studies consignam uma perspectiva resolutamente antidogmática. 
pelas práticas e ações cotidianas, por intermédio de invocações reiteradas de conceitos e terminologias jurídicas, assim como a partir de associações imaginativas e inabituais.

Logo, Ewick e Silbey (1998) distinguem "direito" (Law) e "legalidade" (legality). ${ }^{41}$ Segundo Silbey (2018), esses dois conceitos exprimiriam os esforços de sintetizar, em um nível de maior abstração, o que se passa, de um lado, no plano leigo, informal, cotidiano e, de outro, no institucional. ${ }^{42}$ Assim, a "legalidade", como "construto analítico", afigura-se como fundamental na proposta das autoras. Para sustentar a definição de "legalidade" como "componente estrutural da sociedade", Ewick e Silbey (1998) mobilizam a noção de "estrutura” proposta por William H. Sewell Jr. que, por sua vez, é construída a partir da mobilização crítica da noção de "dualidade da estrutura" de Anthony Giddens e do conceito de "habitus" de Pierre Bourdieu. ${ }^{43}$ Não cabe aqui reconstruir a complexa proposta de Sewell Jr. (1992) nem analisar o modo pelo qual ela é apropriada por Ewick e Silbey (1998) para definir a legalidade. O propósito dessa alusão foi apenas ressaltar o quanto a questão da interdisciplinaridade está no âmago da perspectiva das autoras que, como visto, é central no âmbito dos Legal Consciousness Studies.

3. A afinidade entre os Legal Consciousness Studies e a pesquisa sociojurídica francesa: notas a partir do dossiê do centésimo número da revista Droit et Société

$\mathrm{Na}$ apresentação do dossiê comemorativo da publicação do centésimo número da revista Droit et Société, Commaille e Lacour (2018) apontam a importância dos Legal Consciousness Studies no âmbito da pesquisa sociojurídica norte-americana e o seu impacto na França. Nesse particular, ressaltam que tais estudos manteriam significativa afinidade com um regime de produção de conhecimento sobre o direito que, no contexto acadêmico francês, estaria em ruptura relativamente às abordagens dominantes. Ora, como

${ }_{41}$ Nesse particular, malgrado as especificidades teóricas próprias a cada perspectiva, seria fortemente elucidativo explorar os paralelos entre a distinção law/legality, proposta por Ewick e Silbey (1998), e a distinção droitjuridicité, propugnada por Le Roy (1998, 1999, 2007, 2013 e 2017). Esse contraste, entretanto, não é compatível com os propósitos da presente análise e será objeto de outro artigo. Acerca da "teoria do multijuridismo" de Étienne Le Roy, ver: Eberhard (2001 e 2010) e Villas Bôas Filho (2014, 2015b, 2015c, 2015d e 2017a). Para uma breve alusão à perspectiva de Patricia Ewick e Susan Silbey no âmbito da antropologia jurídica francófona, ver: Kourilsky-Augeven (2009).

42 Nesse sentido Kourilsky-Augeven (2009, p. 259) ressalta que "l'approche théorique de la conscience juridique développée par P. Ewick et S. Silbey va, pour un lecteur européen de formation juridique, assez loin dans la remise en question du champ du droit. Allant au-delà de l'interrogation classique sur le rôle du droit (Law) dans les rapports sociaux, elles décrivent le rôle clé joué par 'la présence ordinaire de la legality' ou du 'juridique' dans la vie des individus".

43 Procurando desenvolver uma "teoria da estrutura", Sewell Jr. (1992, p. 4) afirma que "my strategy will be to begin from what I regard as the most promising existing formulations - Anthony Giddens's notion of 'the duality of structure' and, at a later point in the argument, Pierre Bourdieu's concept of habitus - and to develop a more adequate theory by means of critique, reformulation, and elaboration". 
visto, essa é exatamente uma das premissas fundamentais que norteiam a linha editorial da revista Droit et Société: a crítica ao dogmatismo que viceja nos estudos e na formação jurídica. ${ }^{44}$ É por esse motivo que Commaille (2018) sustenta, enfaticamente, o caráter inovador dos Legal Consciousness Studies que, em seu entendimento, constituiriam um "novo paradigma" para a pesquisa acerca do direito.

Nesse sentido, todas as contribuições que compõem o dossiê do centésimo número da revista Droit et Société procuram explicitar a importância dos Legal Consciousness Studies e, em especial, da obra de Susan Silbey, para o tipo de pesquisa que, no contexto acadêmico francês, assumem um viés crítico e antidogmático de pesquisa no tocante à regulação jurídica. ${ }^{45}$ A esse respeito, Chappe, Pélisse e Egea (2018), procurando fazer um balanço crítico da importação e dos usos dos Legal Consciousness Studies no espaço acadêmico francófono, mapeiam, mediante uma análise qualitativa, a recepção de algumas das referências centrais desses estudos ressaltando a centralidade do livro The common place of law: stories from everyday life, de Patricia Ewick e Susan Silbey. ${ }^{46}$ Chappe, Pélisse e Egea (2018) também aludem às principais referências da produção francófona que dialoga ou apresenta os Legal Consciousness Studies. ${ }^{47}$ A reprodução adaptada do quadro faz-se significativa para a presente análise.

44 A respeito, ver, especialmente: Arnaud (1992), Arnaud, Commaille e Ost (1999) e Brunet e Dumoulin (2018).

45 A discussão crítica da obra de Susan Silbey, escolhida como objeto do dossiê do centésimo número da revista Droit et Société, congrega os seguintes autores: Jacques Commaille, Stéphane Lacour, Anne Wyvekens, Virgine Albe, Daniela Piana, Emilia Schijman, Noé Wagener, Vincent-Arnaud Chappe, Jérôme Pélisse e Anna Egea.

46 Embora não haja estudo semelhante a esse no Brasil, parece possível afirmar que também aqui essa obra ocupa um lugar central na recepção dos Legal Consciousness Studies.

47 Chappe, Pélisse e Egea (2018, p. 670) apresentam um quadro que se concentra nos textos de Chantal Kourilsky-Augeven, Jérôme Pélisse e Liora Israël e nas duas traduções, para o francês, do terceiro capítulo do livro The common place of law: stories from everyday life, de Patricia Ewick e Susan Silbey. Embora não esteja contemplado pelo quadro, é relevante aqui um artigo de Mauricio García Villegas, publicado na revista Droit et Société, em 2003. A respeito, ver: García Villegas (2003), Pélisse (2005) e Commaille e Lacour (2018). 


\section{Quadro 2}

Seis produções francófonas que traduzem ou apresentam os Legal Consciousness Studies

\begin{tabular}{|c|c|}
\hline Título da referência & Razão da inclusão no corpus da pesquisa \\
\hline $\begin{array}{l}\text { EWICK, Patricia; SILBEY, Susan S. Devant } \\
\text { la loi: la construction sociale du juridique. In: } \\
\text { KOURILSKY-AUGEVEN, Chantal (dir.). } \\
\text { Socialisation juridique et conscience du droit: } \\
\text { attitudes individuelles, modèles culturels et } \\
\text { changement social. Paris: MSH-LGDJ, 1997. p. } \\
\text { 33-56. }\end{array}$ & $\begin{array}{l}\text { Primeira tradução do capítulo } 3 \text { do livro The } \\
\text { common place of law: stories from everyday life, } \\
\text { de Patricia Ewick e Susan Silbey. }\end{array}$ \\
\hline $\begin{array}{l}\text { KOURILSKY-AUGEVEN, Chantal. Legal } \\
\text { Consciousness Studies et sociologie juridique: } \\
\text { pour une dialogue franco-américain. Droit et } \\
\text { Cultures, Paris, n. 35, p. 7-13, } 1998 \text {. }\end{array}$ & $\begin{array}{l}\text { Artigo que introduz um dossiê que apresenta os } \\
\text { Legal Consciousness Studies aos pesquisadores } \\
\text { francófonos. }\end{array}$ \\
\hline $\begin{array}{l}\text { PÉLISSE, Jérôme. Consciences du temps et } \\
\text { consciences du droit chez des salariés à } 35 \text { h. Droit } \\
\text { et Société, Paris, n. 53, p. 163-186, 2003. }\end{array}$ & $\begin{array}{l}\text { Artigo que apresenta, utiliza e propõe uma série } \\
\text { de críticas aos Legal Consciousness Studies. }\end{array}$ \\
\hline $\begin{array}{l}\text { ISRAËL, Liora; PÉLISSE, Jérôme. Quelques } \\
\text { éléments sur les conditions d'une 'importation' } \\
\text { (note liminaire à la traduction du texte de S. Silbey } \\
\text { et P. Ewick. Terrain et Travaux, Cachan, n. 6, p. } \\
\text { 101-111, 2004. }\end{array}$ & $\begin{array}{l}\text { Nota introdutória que discute as condições de } \\
\text { importação dos Legal Consciousness Studies. }\end{array}$ \\
\hline $\begin{array}{l}\text { EWICK, Patricia; SILBEY, Susan S. La } \\
\text { construction sociale de la légalité. Terrain et } \\
\text { Travaux, Cachan, n. 6, p. 112-138, } 2004 \text {. }\end{array}$ & $\begin{array}{l}\text { Segunda tradução do capítulo } 3 \text { do livro The } \\
\text { common place of law: stories from everyday life, } \\
\text { de Patricia Ewick e Susan Silbey, realizada pelos } \\
\text { estudantes da ENS Cachan. }\end{array}$ \\
\hline $\begin{array}{l}\text { PÉLISSE, Jérôme. A-t-on conscience du droit? } \\
\text { Autour des Legal Consciousness Studies. Genèses, } \\
\text { Paris, n. 59, p. 114-130, } 2005 .\end{array}$ & $\begin{array}{l}\text { Artigo que apresenta, aponta certos limites e } \\
\text { reflete sobre as condições de importação dos } \\
\text { Legal Consciousness Studies. }\end{array}$ \\
\hline
\end{tabular}

Adaptado de Chappe, Pélisse e Egea (2018, p. 670)

Com o propósito de sublinhar a consonância de propósitos das análises desenvolvidas no bojo dos Legal Consciousness Studies, em especial, da obra de Susan Silbey com os estudos veiculados pela revista Droit et Société, será feita a seguir uma breve menção (e não mais do que isso) às suas afinidades com a "sociologia política do direito" de Jacques Commaille, ${ }^{48}$ uma vez que, como visto, esse autor, além de ser um

48 García Villegas (2015) ressalta a influência das correntes americanas Legal Consciousness Studies e Cause Lawyering sobre a "sociologia política do direito" de Jacques Commaille. Vale notar, entretanto, que Commaille (2018) apresenta certas reservas relativamente à perspectiva de Susan Silbey, especialmente no 
dos fundadores da referida publicação, também é uma das figuras centrais na definição de sua linha editorial. Tendo isso em conta, vale notar, em primeiro lugar, que, ao sustentar a imersão social e política da regulação jurídica, Commaille (2018) realça a consonância de propósitos de sua "sociologia política do direito" com as análises desenvolvidas no bojo dos Legal Consciousness Studies e, em especial, com a obra de Susan Silbey. ${ }^{49}$ Além disso, outro aspecto comum a essas duas perspectivas consiste na crítica a uma visão instrumentalista da sociologia jurídica. ${ }^{50}$ Por fim, há também a ênfase na questão do poder como um aspecto importante tanto para a "sociologia política do direito" quanto para os Legal Consciousness Studies. ${ }^{51}$

\section{4. À guisa de conclusão: Droit et Société e a pesquisa interdisciplinar}

O presente artigo procurou analisar a questão da interdisciplinaridade nos estudos sociojurídicos a partir da expressiva experiência editorial da revista Droit et Société, fundada, em 1985, por André-Jean Arnaud, Jacques Commaille e JeanFrançois Perrin. Assim, focalizando especialmente o dossiê do centésimo número da revista, publicado em dezembro de 2018, com o título "After Legal Consciousness Studies: dialogues transatlantiques et transdisciplinaires", o artigo pretendeu explicitar

que concerne à sua ênfase na legal hegemony.

49 Analogamente, no texto de apresentação de um volume da revista L'Année Sociologique dedicado à "sociologia política do direito", Commaille e Duran (2009, p. 15) afirmam que "c'est dans ce contexte de bouleversements que s'impose la nécessité d'une sociologie politique du droit où le droit apparaît comme immergé dans le social et le politique. Il est ainsi de plus en plus appréhendé comme le produit d'une construction sociale, institutionnelle et politique à laquelle concourent les professionnels du droit et les savoirs juridiques. Profondément inscrit politiquement, le droit apparaît également profondément inscrit socialement. Rien ne l'illustre mieux que la thèse tenue au sein d'un courant américain dit du 'legal consciousness'. Suivant cette thèse, il s'agit de rompre avec une vision causale qui conduisait notamment à poser le problème en termes d'effectivité ou en termes d'influences réciproques entre le juridique et le social. Le droit est ici conçu comme constitutif de la réalité sociale et non pas comme relevant d'une sphère autonome dont il conviendrait d'observer les relations avec le social". Por outro lado, Silbey (2005 e 2018) ressalta que os Legal Consciousness Studies, derivados que são dos Law and Society Studies, concebem o direito como imergido na teia de relações sociais.

50 Referindo-se aos Legal Consciousness Studies, Commaille e Lacour (2018, p. 549) ressaltam que "la perspective au fondement de ce courant est à l'opposé de ce qui a caractérisé - aux yeux des juristes comme des sociologues eux-mêmes - la sociologie du droit française, une sociologie fortement dépendante de l'univers juridique et conçue, à ce titre, comme une ingénierie sociale au service de l'amélioration du droit, droit de l'État à titre quasi exclusif'. Sobre essa questão, ver: Silbey (2005 e 2018) e García Villegas (2015).

51 A respeito, ver: Commaille (2010, 2015 e 2018) e Silbey (2005 e 2018). Não é despiciendo notar que, por ocasião das Jornadas de Estudos dedicadas à "sociologia política do direito", em setembro de 2013, como homenagem a Jacques Commaille, no Institut des Sciences Sociales du Politique da École Normale Supérieure Paris-Saclay, a conferência de encerramento da primeira jornada foi realizada por Susan Silbey. Nesse evento, designado Sociologie politique du droit - Quels acquis? Quelles perspectives? Journées en l'honneur de Jacques Commaille, foi apresentado e discutido o texto intitulado "Une sociologie politique du droit", de Jacques Commaille, cuja versão em português foi veiculada pela Revista da Faculdade de Direito da Universidade de São Paulo em seu volume 108. A respeito, ver: Commaille (2013b). 
a questão da interdisciplinaridade como marca constitutiva e como diretriz básica dos estudos veiculados por essa expressiva publicação francesa. ${ }^{52}$ Portanto, mediante a análise de editoriais publicados em momentos distintos da revista, buscou-se mostrar o seu compromisso relativamente às balizas que desde sempre a nortearam: antidogmatismo, interdisciplinaridade e internacionalidade. ${ }^{53}$

Assim, realizou-se, em primeiro lugar, uma breve referência à proposta de André-Jean Arnaud de desenvolvimento dos estudos sociojurídicos como um campo de pesquisa interdisciplinar e à "sociologia política do direito" de Jacques Commaille. Como ressaltado, essa concisa digressão teve sua importância em razão da ascendência intelectual de ambos os autores sobre a linha editorial da revista Droit et Société. Em seguida, foi feita uma breve incursão pela obra de Susan Silbey, figura central no bojo dos Legal Consciousness Studies, ressaltando fundamentalmente o seu contorno interdisciplinar, com o intuito de explicitar uma das razões fundamentais de sua escolha como objeto do dossiê do centésimo número da revista Droit et Société. Por fim, foi feita uma suscinta alusão à recepção dos Legal Consciousness Studies e, em particular, da obra de Susan Silbey, no âmbito dos estudos sociojurídicos na França, com especial ênfase nas afinidades existentes entre eles e a "sociologia política do direito" de Jacques Commaille.

São Paulo, 30 de abril de 2019.

\section{Referências}

ARNAUD, André-Jean. Critique de la raison juridique: 1. Où va la sociologie du droit? Paris: LGDJ, 1981. (Bibliothèque de Philosophie du Droit, v. 26).

. Éditorial. Droit et Société, Paris, n. 1, p. 5-6, 1985.

. Droit et société: un carrefour interdisciplinaire. Revue Interdisciplinaire d'Études Juridiques, Bruxelles, v. 21, p. 7-32, 1988.

. O direito traído pela filosofia. Tradução de Wanda de Lemos Capeller e Luciano Oliveira. Porto Alegre: Fabris Ed., 1991.

. Droit et Société: du constat à la construction d'un champ commun. Droit et Société, Paris, n. 20-21, p. 17-38, 1992.

. Le droit comme produit. Présentation du dossier sur la norme de la production juridique. Droit et Société, Paris, n. 27, p. 293-301, 1994.

\footnotetext{
52 Trata-se de um aspecto que pude observar, ainda que de forma assistemática, desde 2009, na qualidade de membro do Comitê Editorial e correspondente lusófono da revista Droit et Société.

53 Cf. Arnaud, Commaille e Ost (1999).
} 
ARNAUD, André-Jean. Le droit trahi par la sociologie: une pratique de 1'histoire. Paris: LGDJ, 1998.

. Regards croisés sur la notion de droit en contexte. Revue Interdisciplinaire d'Études Juridiques, Bruxelles, v. 70, n. 1, p. 45-53, 2013.

. La gouvernance. Un outil de participation. Paris: LGDJ, 2014.

; COMMAILlE, Jacques. Présentation. Droit et Société, Paris, n. 7, p. 323-324, 1987.

; __ Éditorial. Droit et Société, Paris, n. 91, p. 453-457, 2015.

; __ _ _ OST, François. Éditorial. Droit et Société, Paris, n. 42-43, p. 231-236, 1999.

; FARIÑAS DULCE, María-José. Introduction à l'analyse sociologique des systèmes juridiques. Bruxelles: Emile Bruylant, 1998.

BAILLEUX, Antoine; OST, François. Droit, contexte et interdisciplinarité: refondation d'une démarche. Revue Interdisciplinaire d'Études Juridiques, Bruxelles, v. 70, n. 1, p. 25-44, 2013.

BOURDIEU, Pierre. Habitus, code et codification. Actes de la Recherche en Sciences Sociales, Paris, v. 64, p. 40-44, Sept. 1986a.

. La force du droit. Éléments pour une sociologie du champ juridique. Actes de la Recherche en Sciences Sociales, Paris, v. 64, p. 3-19, Sept. 1986b.

. Les juristes, gardiens de l'hypocrisie collective. In: CHAZEL, François; COMMAILLE, Jacques (dir.). Normes juridiques et régulation sociale. Paris: LGDJ, 1991. p. 95-99.

. Esprits d'État: genèse et structure du champ bureaucratique. Actes de la Recherche en Sciences Sociales, Paris, v. 96-97, p. 49-62, Mars 1993.

. Sur l'état. Cours au collège de France 1989-1992. Paris: Raisons d'agir/Éditions du Seuil, 2012.

. Sociologie générale. Cours au Collège de France (1981-1983). Paris: Raisons d'agir/ Éditions du Seuil, 2015. v. 1.

. Sociologie générale. Cours au Collège de France (1983-1986). Paris: Raisons d'agir/ Éditions du Seuil, 2016. v. 2.

; CHAMBOREDON, Jean-Claude; PASSERON, Jean-Claude. Le métier de sociologue: préalables épistémologiques. $5^{\mathrm{e}}$ éd. Berlin: Mouton de Gruyter, 2005.

BRUNET, Pierre; DUMOULIN, Laurence. Éditorial. Droit et Société, Paris, n. 100, p. 539-541, 2018.

CAILLOSSE, Jacques. La sociologie politique du droit, le droit et les juristes. Droit et Société, Paris, n. 77, p. 187-206, 2011.

CAMPILONGO, Celso Fernandes. Direito e democracia. 2. ed. São Paulo: Max Limonad, 2000. 
CAPELLER, Wanda. André-Jean Arnaud: uma obra de transgressão. In: ARNAUD, André-Jean. $O$ direito traído pela filosofia. Tradução de Wanda de Lemos Capeller e Luciano Oliveira. Porto Alegre: Fabris Ed., 1991. p. 7-21.

. Du 'cercle' à Droit et Société, une sociologie du droit semblable aux abeilles. In:

COMMAILLE, Jacques; ORTIZ, Laure (dir.). Repenser le droit: hommage à André-Jean Arnaud. Paris: LGDJ, 2019. p. 21-33.

CHAPPE, Vincent-Arnaud; PÉLISSE, Jérôme; EGEA, Anna. Importations, diffusions et inflexions des Legal Consciousness Studies dans la recherche française. Droit et Société, Paris, n. 100, p. 665684, 2018.

COMMAILLE, Jacques. L'interdisciplinarité aux regards de la sociologie. Droit et Société, Paris, n. 10, p. 525-527, 1988.

. Éditorial. Droit et Société, Paris, n. 20-21, p. 13-14, 1992.

. L'esprit sociologique des lois: essai de sociologie politique du droit. Paris: PUF, 1994.

. La construction d'une sociologie spécialisée. Le savoir sociologique et la sociologie juridique de Jean Carbonnier. L'Année Sociologique, Paris, v. 57, n. 2, p. 275-299, 2007.

. De la "sociologie juridique" à une sociologie politique du droit. In: ; DUMOULIN, Laurence; ROBERT, Cécile (dir.). La juridicisation du politique. Paris: LGDJ, 2010. p. 29-51.

- Les nouveaux enjeux épistémologiques de la mise en contexte du droit. Revue Interdisciplinaire d'Études Juridiques, Bruxelles, v. 70, n. 1, p. 62-69, $2013 \mathrm{a}$.

. Uma sociologia política do direito. Revista da Faculdade de Direito da Universidade de São Paulo, São Paulo, v. 108, p. 929-933, jan./dez. 2013 b.

. À quoi nous sert le droit? Paris: Folio, 2015.

. À quoi nous sert le droit pour comprendre sociologiquement les incertitudes des sociétés contemporaines? SociologieS [En ligne], Dossiers, Sociétés en mouvement, p. 1-12, 2016. Disponível em: http://sociologies.revues.org/5278. Acesso em: 7 mar. 2016.

. Les Legal Consciousness Studies selon Susan Silbey: une dissonance entre données empiriques et ressources théoriques? Droit et Société, Paris, n. 100, p. 657-664, 2018.

- Métamorphoses de la justice et nouveaux régimes de régulation sociale et politique des sociétés contemporaines. In: ; ALBE, Virginie; LE BOT, Florent (dir.). L'échelle des régulations politiques, $X V I I I^{e}-X X I^{e}$ siècles: l'histoire et les sciences sociales aux prises avec les normes, les acteurs et les institutions. Villeneuve d'Ascq: Presses Universitaires de Septentrion, 2019. p. 223-245.

; DURAN, Patrice. Pour une sociologie politique du droit: présentation. L'année Sociologique, Paris, v. 59, n. 1, p. 11-28, 2009. 
COMMAILLE, Jacques; LACOUR, Stéphanie. Les Legal Consciousness Studies comme laboratoire d'un régime renouvelé de connaissance sur le droit. Présentation du dossier. Droit et Société, Paris, n. 100, p. 547-558, 2018.

CONDÉ, Pierre-Yves. Droit et Société, ou le pluralisme d'une revue de théorie et sciences sociales du droit. Droit et Société, Paris, n. 91, p. 687-718, 2015.

CORTEN, Olivier. Éléments de définition pour une sociologie politique du droit. Droit et Société, Paris, n. 39, p. 347-370, 1998.

DELPEUCH, Thierry; DUMOULIN, Laurence; GALEMBERT, Claire de. Sociologie du droit et de la justice. Paris: Armand Colin, 2014.

DUMONT, Hugues; BAILLEUX, Antoine. Esquisse d'une théorie des ouvertures interdisciplinaires accessibles aux juristes. Droit et Société, Paris, n. 75, p. 275-293, 2010.

EBERHARD, Christoph. Towards an intercultural legal theory: the dialogical challenge. Social \& Legal Studies, Thousand Oaks, v. 2, n. 2, p. 171-201, Jun. 2001.

. Le droit au miroir des cultures. Pour une autre mondialisation. Paris: LGDJ, 2010.

EWICK, Patricia; SILBEY, Susan S. The common place of law: stories from everyday life. Chicago: University of Chicago Press, 1998.

FERREIRA, António Casimiro; PEDROSO, João. Pour une "sociologie du droit renouvelée": de la critique de la raison juridique à la gouvernance. In: CAPELLER, Wanda; COMMAILLE, Jacques; ORTIZ, Laure (dir.). Repenser le droit: hommage à André-Jean Arnaud. Paris: LGDJ, 2019. p. 193204.

GARCÍA VILLEGAS, Mauricio. On Pierre Bourdieu's legal thought. Droit et Société, Paris, n. 5657, p. 57-70, 2004.

. Symbolic Power without Symbolic Violence? Critical Comments on Legal Consciousness Studies in USA. Droit et Société, Paris, n. 53, p. 137-163, 2003.

2015.

. Les pouvoirs du droit. Analyse comparée d'études sociopolitiques du droit. Paris: LGDJ,

GUIBENTIF, Pierre. Foucault, Luhmann, Habermas, Bourdieu. Une génération repense le droit. Paris: LGDJ, 2010.

HUNT, Alan. The sociological movement in law. London: MacMillan, 1978.

KOURILSKY-AUGEVEN, Chantal. Socialisation, socialisation juridique et conscience du droit. In: RUDE-ANTOINE, Edwige; CHRÉTIEN-VERNICOS, Geneviève (coord.). Anthropologies et droits: état des savoirs et orientations contemporaines. Paris: Dalloz, 2009. p. 246-269. 
LE ROY, Étienne. L'hypothèse du multijuridisme dans un contexte de sortie de modernité. In: LAJOIE, André; MACDONALD, Roderick A.; JANDA, Richard; ROCHER, Guy. Théories et émergence du droit: pluralisme, surdétermination et effectivité. Montréal: Les Éditions Thémis, 1998. p. 29-43.

. Le jeu des lois. Une anthropologie «dynamique» du droit. Avec des consignes et des conseils au «jeune joueur juriste». Paris: LGDJ, 1999.

. Le tripode juridique. Variations anthropologiques sur un thème de «flexible droit». L'Année Sociologique, Paris, v. 57, n. 2, p. 341-351, 2007.

. Place de la juridicité dans la médiation. Jurisprudence - Revue Critique, Chambéry, n. 4 (La médiation. Entre renouvellement de l'offre de justice et droit), p. 193-208, 2013.

2017.

. Une juridicité plurielle pour le XXI siècle. Sarrebruck: Éditions Universitaires Européennes,

ORTIZ, Laure. La gouvernance, l'outil d'une pensée juridique projective. In: CAPELLER, Wanda; COMMAILLE, Jacques; ORTIZ, Laure (dir.). Repenser le droit: hommage à André-Jean Arnaud. Paris: LGDJ, 2019. p. 223-232.

OST, François. In memoriam - André-Jean Arnaud (1936-2015). Revue Interdisciplinaire d'Études Juridiques, Bruxelles, v. 76, n. 1, p. 1-3, 2016.

PÉLISSE, Jérôme. A-t-on conscience du droit? Autour des Legal Consciousness Studies. Genèses, Paris, n. 59, p. 114-130, 2005.

PERRIN, Jean-François. Genèse de la revue Droit et Société. In: CAPELLER, Wanda; COMMAILLE, Jacques; ORTIZ, Laure (dir.). Repenser le droit: hommage à André-Jean Arnaud. Paris: LGDJ, 2019. p. 35-40.

RAIMBAULT, Philippe; SIMOULIN, Vincent. Les collections de Droit et Société: une entreprise humaine et exaltante. In: CAPELLER, Wanda; COMMAILLE, Jacques; ORTIZ, Laure (dir.). Repenser le droit: hommage à André-Jean Arnaud. Paris: LGDJ, 2019. p. 41-48.

ROULAND, Norbert. Retour du Brésil: impressions d'un juriste anthropologue français. Paris: L'Harmattan, 2018.

ROUSSEL, Violaine. Le droit et ses formes. Éléments de discussion de la sociologie du droit de Pierre Bourdieu. Droit et Société, Paris, n. 56-57, p. 41-55, 2004.

SCKELL, Soraya Nour. Os juristas e o direito em Bourdieu: a conflituosa construção histórica da racionalidade jurídica. Tempo Social, São Paulo, v. 28, n. 1, p. 157-178, abril 2016.

SEWELL JR., William H. A theory of structure: duality, agency, and transformation. American Journal of Sociology, Chicago, v. 98, n. 1, p. 1-29, Jul. 1992. 
SILBEY, Susan S. After legal consciousness. Annual Law Review of Law and Social Science, Palo Alto, v. 1, p. 323-368, 2005.

. Studying Legal Consciousness: building institutional theory from micro data. Droit et Société, Paris, n. 100, p. 685-731, 2018.

SUEUR, Jean-Jacques. Pierre Bourdieu, le droit et les juristes. La méprise. Droit et Société, Paris, n. 85, p. $725-753,2013$.

VILLAS BÔAS FILHO, Orlando. Juridicidade: uma abordagem crítica à monolatria jurídica enquanto obstáculo epistemológico. Revista da Faculdade de Direito da Universidade de São Paulo, São Paulo, v. 109, p. 281-325, jan./dez. 2014.

. A juridicização e a judiciarização enfocadas a partir da "sociologia política do direito" de Jacques Commaille. Revista Brasileira de Sociologia do Direito, Recife, v. 2, n. 2, p. 56-75, jul./ dez. 2015a.

. A questão da universalidade das categorias jurídicas ocidentais a partir da abordagem antropológica: nota sobre a discussão entre Max Gluckman e Paul Bohannan. Revista da Faculdade de Direito da Universidade de São Paulo, São Paulo, v. 110, p. 277-318, jan./dez. 2015 b.

. A regulação jurídica para além de sua forma ocidental de expressão: uma abordagem a partir de Étienne Le Roy. Revista Direito \& Práxis, Rio de Janeiro, v. 6, n. 12, p. 159-195, 2015c.

. O direito de qual sociedade? Os limites da descrição sociológica de Niklas Luhmann acerca do direito a partir da crítica antropológica. In: FEBBRAJO, Alberto; LIMA, Fernando Rister de Sousa; PUGLIESI, Márcio (coord.). Sociologia do direito: teoria e práxis. Curitiba: Juruá, 2015 d. p. 341-370.

. A governança em suas múltiplas formas de expressão: o delineamento conceitual de um fenômeno complexo. Revista Estudos Institucionais, Rio de Janeiro, v. 2, n. 2, p. 670-706, 2016a.

. O impacto da governança sobre a regulação jurídica contemporânea: uma abordagem a partir de André-Jean Arnaud. REDES - Revista Eletrônica Direito e Sociedade, Canoas, v. 4, n. 1, p. 145-171, 2016b.

. A mediação em um campo de análise interdisciplinar: o aporte da teoria do multijuridismo de Étienne Le Roy. Revista Estudos Institucionais, Rio de Janeiro, v. 3, n. 2, p. 1.112-1.162, 2017a. . André-Jean Arnaud: l'homme derrière l'œuvre. Revista da Faculdade de Direito da Universidade de São Paulo, São Paulo, v. 112, p. 323-343, jan./dez. 2017 b.

. O desenvolvimento dos estudos sociojurídicos: da cacofonia à construção de um campo de pesquisa interdisciplinar. Revista da Faculdade de Direito da Universidade de São Paulo, São Paulo, v. 113, p. 251-292, jan./dez. 2018a. 
VILLAS BÔAS FILHO, Orlando. Por um delineamento conceitual da complexidade social: as experiências do Mercosul e do orçamento participativo na análise de André-Jean Arnaud sobre a governança. Novos Estudos Jurídicos, Itajaí, v. 23, n. 2, p. 491-520, 2018 b.

. Uma proposta alternativa de modelização sistêmica para a análise crítica da regulação jurídica: a perspectiva de André-Jean Arnaud. In: AMATO, Lucas Fucci; BARROS, Marco Antonio Loschiavo Leme de (org.). Teoria crítica dos sistemas? Crítica, teoria social e direito. Porto Alegre: Editora Fi, 2018c. p. 321-360.

. Ce que la sociologie juridique de l'Amérique Latine doit à André-Jean Arnaud: l'exemple de l'analyse de l'expérience du Mercosur dans le cadre de son étude de la gouvernance. In: CAPELLER, Wanda; COMMAILLE, Jacques; ORTIZ, Laure (dir.). Repenser le droit: hommage à André-Jean Arnaud. Paris: LGDJ, 2019a. p. 101-110.

. Desafios da pesquisa interdisciplinar: as ciências sociais como instrumentos de "vigilância epistemológica" no campo dos estudos sociojurídicos. Revista Estudos Institucionais, Rio de Janeiro, v. 5, n. 2, p. 530-558, maio/ago. 2019b.

WYVEKENS, Anne. Aux origines des Legal Consciousness Studies. Susan Silbey, observatrice et actrice. Droit et Société, Paris, n. 100, p. 627-631, 2018. 
